\title{
Intrapersonal Factors Affecting Academic Probation Students in Universiti Teknologi PETRONAS
}

\author{
Nurul Fatihah Amir ${ }^{1}$, Thibankumar Arumugam ${ }^{2}$, and Saravanan Karuppanan ${ }^{2}$ \\ ${ }^{1}$ Psychology and Counselling Department, Universiti Teknologi PETRONAS, 32610 Bandar Seri \\ Iskandar, Perak Darul Ridzuan, Malaysia \\ ${ }^{2}$ Mechanical Engineering Department, Universiti Teknologi PETRONAS, 32610 Bandar Seri \\ Iskandar, Perak Darul Ridzuan, Malaysia
}

\begin{abstract}
Academic probation students are considered a risk group as they do not meet the minimum academic requirements for a given semester. As such, factors affecting these students should be determined so that effective support or intervention programs can be carried out to assist this risk group. This paper examines the intrapersonal factors affecting academic probation students, specifically self-management, financial and health factors. Higher Education Needs Inventory for Students (HENIs) surveying tool was utilized on 81 academic probation students from Universiti Teknologi PETRONAS. The criticality of the factors affecting the academic probation students is based on the HENIs index. Data analyses by HENIs indicates that selfmanagement factor is the most critical factor amongst the three factors with a HENIs index of 2.52. Such an index value indicates a high level of seriousness. This is also supported by a positive correlation between selfmanagement factor of academic probation students and suicidal ideation $\left(\mathrm{R}^{2}\right.$ of 0.240; $p$-value of 0.001). Financial and health factors both scored a HENIs index of 2.38 and 2.17 , respectively. These index values indicate a moderate level of seriousness.
\end{abstract}

\section{Introduction}

The academic performance of students has been the top priority for educators as well as the educational institute. It is common practice to measure academic performance of students by their cumulative grade point average (CGPA) or grade point average (GPA). CGPA is the average measure of the examinations' grades for the entire tenure of study while GPA is the measure of the examinations' grades for a particular semester. Research pertaining to academic performance of Malaysian students have been conducted using CGPA (Siraj et al., 2015; Ting et al., 2018; Zakaria et al., 2019) as well as GPA (Bunyaan et al., 2015; Nor \& Ismail, 2015; Ramasamy et al., 2018). CGPA and GPA is a good yardstick in determining the academic performance of students. A high CGPA correlates to a strong academic performance for the entire tenure of study while a high GPA correlates to a strong academic performance for that semester. As such, strong CGPA and GPA performances often lead to favorable graduates (Cheong et al., 2018). 
Based on the report by the Malaysian Ministry of Higher Education, undergraduates make up approximately $79 \%$ of the university population (Malaysian Ministry of Higher Education, 2018) Amongst these, a certain percentage of them do not meet the minimum academic requirement for a given semester. These students are known as academic probation students. Academic probation students are considered a risk group in education institutions, as most of them are unaware of the of their sources of academic weakness and do not utilize the readily available resources (Latif, 2006). Thus, it is critical to further examine factors that affect academic probation students' performance.

Specific factors that affect the academic performance of students are plentiful, and they range from and not limited to the use of social media, socioeconomic class, peer influence etc. One of the main branches of factors that affect academic performance of students is intrapersonal factors. Intrapersonal factors describe factors that occur within an individual, e.g., self-concept, attitude or decision. This paper examines the intrapersonal factors affecting academic probation students, specifically self-management, financial and health factors. Analyses of these interpersonal factors allow for an effective support or intervention programs to be carried out to assist this risk group. A study conducted by Mongermery et al. (2019) proved that certain intrapersonal factors affected the academic adjustment of students. Note that academic adjustment is defined as the ability to cope with educational demands. Amongst the factors studied, adaptive perfectionism correlated to higher academic adjustment which is in line with the research by Rice and Mirzadeh (2000) who stated that certain perfectionist habits could enhance task engagement hence leading to completion. However, maladaptive perfectionism as well as procrastination were found to significantly associated with lower academic adjustment.

Elias et al. (2011) utilized college undergraduate stress scale (CUSS) to determine the correlation between stress and academic achievement. CUSS assesses the student in four aspects including intrapersonal stress. Results of the CUSS assessment revealed three intrapersonal stresses; sense of overload, students hating the subjects because poor understanding of the subject as well as students falling asleep in class because they did not have enough sleep. Winterrowd et al. (2016) found that counselling sessions allowed for a significant improvement in intrapersonal skills and as such allowed for greater ability to focus on academics. The improvements in the intrapersonal skills include improvements in stressmanagement, self-esteem/confidence, critical thinking as well as communication. From an academic viewpoint, students noticed an improvement in academic motivation, attendance as well as retention of students who initially considered dropping out.

\section{Methods}

\subsection{Study design and participants}

A cross-sectional study was conducted on academic probation students of Universiti Teknologi PETRONAS (UTP). Academic probation students are determined by a GPA of less than 2.0 (based on the 4.0) scale of a certain semester. Purposive sampling technique was used to determine the intrapersonal factors affecting 147 academic probation students, however, only 81 of them provided complete data necessary for this study.

\subsection{Procedure}


This is a pilot study utilizing Higher Education Needs Inventory for Students (HENIs) surveying tool conducted by the Psychological and Counselling Department of UTP. The academic probation students were asked to complete the HENIs survey within a week of the email distribution.

\subsection{Materials}

HENIs is an online surveying tool that assists analyse students' responses in eight areas, i.e., self, health, spiritual, finance, family, peers, lecturers, and learning environment. Since this study is scoped towards intrapersonal factors, only responses related to intrapersonal factors, i.e., health, spiritual, self-management, addiction, financial, academic were addressed. Through the analyses of the students' responses, HENIs would determine the criticality of the intrapersonal factors affecting the students and provides recommended intervention methods for those factors. HENIs on its own consists of 135 questions, however it also provides 21 questions based on DASS-21, and 16 question based on a modified Orden's Thwarted Belongingness and Perceived Burdensomeness questionnaire. HENIs' 135 questions are based on a 5-point Likert scale. The scale's values are coded as $1=$ Not Relevant, $2=$ Not Critical, $3=$ Less Critical, $4=$ Critical, $5=$ Very Critical.

\subsection{Data Analysis}

Data analysis is done by the HENIs surveying tool using the simple average method. HENIs then outputs the criticality of a factor by its own index (known as the HENIs Index) as tabulated in Table 1. The HENIs Index provides a measure of criticality of the factors affecting the respondents.

Table 1. The HENIs Index with its corresponding remarks.

\begin{tabular}{|c|l|}
\hline HENIs Index Range & \multicolumn{1}{c|}{ Remarks } \\
\hline $1.00-1.50$ & $\begin{array}{l}\text { Low level of problem seriousness. This level indicates non-serious } \\
\text { problem with very few students facing the problem in the category. } \\
\text { For a score of 1.00, it indicates that no one is facing the problem. }\end{array}$ \\
\hline $1.51-2.50$ & $\begin{array}{l}\text { A moderate level of problem seriousness. This level indicates that } \\
\text { there are students with serious issues in the category of problems. } \\
\text { Despite being at the moderate level, organization is advised to take } \\
\text { precautionary measures so that the problem does not deteriorate and } \\
\text { can be resolved immediately. }\end{array}$ \\
\hline \multirow{3}{*}{$3.51-3.50$} & $\begin{array}{l}\text { Referring to a high level of problem seriousness that require } \\
\text { immediate intervention. This level indicates that most of the students } \\
\text { are facing serious issues in the category of problems. Organization } \\
\text { is advised to have discussions with relevant parties for appropriate } \\
\text { intervention. }\end{array}$ \\
\hline $3.51-5.00$ & $\begin{array}{l}\text { Referring to the highest level of problem seriousness with regard to } \\
\text { the category of problems. This level usually indicates that majority } \\
\text { of the students are facing serious problem in that category. } \\
\text { Organization is advised to take immediate action since the issue may } \\
\text { affect student performance and their well-being. }\end{array}$ \\
\hline
\end{tabular}

The sum criticality is used to rank the specific factors from respective factors that affected the respondents. The sum criticality is determined by cumulating the respondents that selected Less Critical, Critical and Very Critical.

\section{Results}


Table 2 lists the intrapersonal factors with its corresponding HENIs Index. As mentioned earlier, the HENIs Index is determined using the simple average method.

Table 2. HENIs Index for the intrapersonal factors that affect the respondents.

\begin{tabular}{|c|c|}
\hline Intrapersonal Factors & HENIs Index \\
\hline Self-management & 2.52 \\
\hline Financial & 2.38 \\
\hline Health & 2.17 \\
\hline Academic & 2.12 \\
\hline Spiritual & 1.85 \\
\hline Addiction & 1.60 \\
\hline
\end{tabular}

HENIs analysis revealed that self-management factor to be the highest intrapersonal factor affecting the respondents with an HENIs index of 2.52. This is followed by financial and health factors with HENIs indices of 2.38 and 2.17, respectively. For brevity, only the top three intrapersonal factors, i.e., self-management, financial, health will be further discussed.

HENIs contains 13 questions for self-management factors, 7 questions for financial factors, and 21 question for health factors. Similarly, for brevity only top 3 questions, determined by the sum criticality, of each factor will be further discussed. Table 3 lists the questions from each intrapersonal factor with its corresponding sum criticality.

Table 3. Top 3 questions from the self-management, financial and health intrapersonal factors.

\begin{tabular}{|c|l|c|}
\hline Intrapersonal Factors & \multicolumn{1}{|c|}{ Questions } & Sum Criticality \\
\hline \multirow{4}{*}{ Self-management } & I like to procrastinate (on) academic task & 61 \\
\cline { 2 - 3 } & I am poor in managing my own time & 55 \\
\cline { 2 - 3 } & I do not feel confident with my own capability & 45 \\
\hline \multirow{3}{*}{ Financial } & I am (a) big spender & 46 \\
\cline { 2 - 3 } & I found it hard to save my money & 44 \\
\cline { 2 - 3 } & I face financial problems & 38 \\
\hline \multirow{3}{*}{ Health } & Headache & 42 \\
\cline { 2 - 3 } & Sleeping problem & 41 \\
\cline { 2 - 3 } & Back pain & 36 \\
\hline
\end{tabular}

\section{Discussion}

Only the top three intrapersonal factors obtained from HENIs were discussed in this section. These are self-management, financial, health with HENIs index of 2.52, 2.38 and 2.17, respectively.

\subsection{Self-management factor}

"I like to procrastinate academic task" is the highest issue when it comes to self-management with a sum criticality of 61 of $81(75.3 \%)$. Kim and Seo (2015) who conducted a metaanalysis of 33 studies revealed that 32 studies supported the notion that procrastination correlates to poor academic performance (i.e., GPA, assignment grade, quiz score as well as course grades). The one study that did not support the positive correlation between procrastination and poor academic performance was by Choi and Moran (2009). Choi and Moran mentioned that procrastination includes active procrastination which is an adaptive behaviour that often leads to satisfactory outcomes such as meeting deadlines, hence not 
leading to poor academic performance. In addition to Kim and Seo's meta-analysis revealing poor academic performance due to procrastination, unnecessary delays in completing tasks has also been linked to negative mood, low levels of self-esteem as well as anxiety (Akinsola et al., 2007).

The second highest issue when it comes to self-management is "I am poor in managing my own time", with a sum criticality of 55 of $81(55.6 \%)$. This can be explained by the fact that relatively good academic performance requires capabilities such as organization of time with execution of duties on schedule, determination of aims, prioritization of tasks, and creating a pattern of studying systematically (Lakshminarayan et al., 2013). Multiple resources have also stated that time management to be an important factor in academic performance where purposeful and structured usage of time especially in learning often leads to good academic performance (Britton \& Tesser, 1991; Macan et al., 1990).

The third highest issue when it comes to self-management is "I do not feel confident with my own capabilities" with a sum criticality of 45 of 71 (55.5\%). Study on nursing students by Kukulu et al. (2013) revealed that high self-confidence often leads to better academic performance. Kukulu et al. also explained self-confidence as the capability to trust one's own abilities, ability to control one's self as well as a strong believe in self-accomplishment. This strongly ties with the definition of self-efficacy which is defined as the confidence level of one's own ability to execute a certain action or accommodating a certain outcome (Lane et al., 2004). Hence, Tice and Baumeister (1997) noted that procrastination among poor academic performers may be attributed to their low levels of self-esteem and self-efficacy.

HENIs was able to recommend the necessary interventions for self-management factors. It was recommended that the students to meet a counsellor for an individual or group counselling session. It was also recommended that a seminar on communication skills and self-esteem to be conducted by the counsellors for the affected students.

\subsection{Financial factor}

The two highest issues when it comes to financial factor are "I am big spender" as well as "I found it hard to save my money" with a sum criticality of $46(56.8 \%)$ and $44(54.3 \%)$ out of 81 , respectively. Since both issues have similar sum criticalities and both refer to similar issues in terms of financial prudency, therefore, these can be addressed as one. Adams and Moore (2007) found that high-risk credit behavior was associated with poor academic performance (lower GPA), however, no causal conclusions could be drawn as the study was correlational. Hogan et al. (2013) noted that students that spent less time studying academic materials were more likely to engage in shopping. It was also stated that the more the students were involved in poor academic behaviors, e.g., skipping classes, the more likely for them to feel anxious, thus leading to frivolous spending.

The next issue when it comes to financial factor is "I face financial problem" with a sum criticality of 38 out of 81 (46.9\%). Benjamin et al. (2011) analyzed the proxy of affordability (average household income) which revealed that students from low to average earning household would struggle to afford private tertiary education in Malaysia. They also proved that the students attending private tertiary education in Malaysia do not receive sufficient financing even with the assistance of subsidized loan such as that provided by the National Higher Education Fund (also known as PTPTN). The more the student feels the responsibility 
in funding their education, the higher their consumer orientation which subsequently results in poorer academic performance (Bunce et al., 2017).

HENIs did not recommend any interventions for financial factors. However, students that report to be burdened with financial issues could be interviewed to determine their eligibility of obtaining bursary from the institution, e.g., via Yayasan UTP.

\subsection{Health factor}

The highest issue when it comes to health is headache with a sum criticality of 42 of 81 $(51.9 \%)$. This result is supported by studies that determined a general high prevalence $(74.5 \%$ to $87.2 \%$ ) of headache presentation amongst undergraduate students (Falavigna et al., 2010; Souza-e-Silva \& Rocha-Filho, 2011). Despite the high prevalence of headache, it was reported that only $8.7 \%$ received medical assistance (Souza-e-Silva \& Rocha-Filho, 2011). Headache amongst undergraduate students has shown to negatively impact the academic performance (Catharino et al., 2007; Rocha-Filho \& Santos, 2014), as well as life routine (Demirkirkan et al., 2006). This is further supported by the fact that students whose headache impacted their life routine were significantly associated with higher number of disciplinary issues as well as poorer academic performance, e.g., higher number of failures (Souza-eSilva \& Rocha-Filho, 2011).

The second highest issue when it comes to health is sleeping problem with a sum criticality of 41 of $81(50.6 \%)$. This result is supported by the study conducted on college students by Yang et al. (2003) who found that $44 \%$ of the students reported sleeping problems, with the most common complaint being lack of sleep time. Gaultney (2010) then reported a significant but weak correlation between more sleep time and better sleep quality with better academic performance. However, they also noted that this correlation should be interpreted with caution due to this weak correlation. A better interpretation was obtained through analyzing students at risk of sleep disorders, e.g., obstructive sleep apnea, insomnia, circadian rhythm disturbances. The analysis revealed that students with sleep disorders showed poor academic performance (GPA < 2.0) (Gaultney, 2010).

The third highest issue when it comes to health is backpain with a sum criticality of 36 of 81 (44.4\%). This result is supported by a study conducted by Issa et al. (2016) who determined that $30 \%$ of the undergraduate students had lower backpain. They also noted that lower backpain was higher among students who were not involved in physical exercise or practice low exercise sessions (less than 3 times/week). However, they also noted that lower backpain is prevalent amongst those with higher academic grades which contradicts with this study. This discrepancy can be explained by sedentary behavior involving the use of digital technology, e.g., smartphone and computer use (Lepp et al., 2013). This is supported by Rainville et al. (2004) that described an increased prevalence of lower backpain among those with sedentary lifestyle. Group et al. (2010) added that poor posture coupled with being sedentary compromises the musculoskeletal system.

HENIs was able to recommend the necessary interventions for health factors. It was recommended that the students to be referred to medical experts as well as to attend a seminar on awareness of physical and mental health. The recommended person-in-charge for this intervention are medical specialists and counsellors.

\subsection{Suicidal ideation}


Results of the Suicidal Ideation Questionnaire from HENIs was utilized to determine the correlation between the suicidal ideation and intrapersonal factors. Linear regression analyses with $95 \%$ confidence interval was conducted between the suicidal ideation and intrapersonal factors. A high value in the intrapersonal factor would reveal that the specific student is having issues pertaining to that intrapersonal factor. Similarly, a high value in suicidal ideation would result in high suicidal ideation tendencies. A summary of the $\mathrm{R}^{2}$ values is as presented in Table 4.

Table 4. Summary of the $\mathrm{R}^{2}$ values of the linear regression analysis between suicidal ideation and intrapersonal factors.

\begin{tabular}{|l|c|}
\hline \multicolumn{1}{|c|}{ Linear Regression Analysis } & $\mathbf{R}^{\mathbf{2}}$ \\
\hline Suicidal ideation against self-management & 0.2400 \\
\hline Suicidal ideation against financial & 0.1011 \\
\hline Suicidal ideation against health & 0.1744 \\
\hline
\end{tabular}

Figure 1 reveals the scatter plot with the regression line of suicidal ideation against selfmanagement. As revealed in Table 4, amongst the intrapersonal factors, self-management revealed the highest $R^{2}$ with a value of 0.2400 .

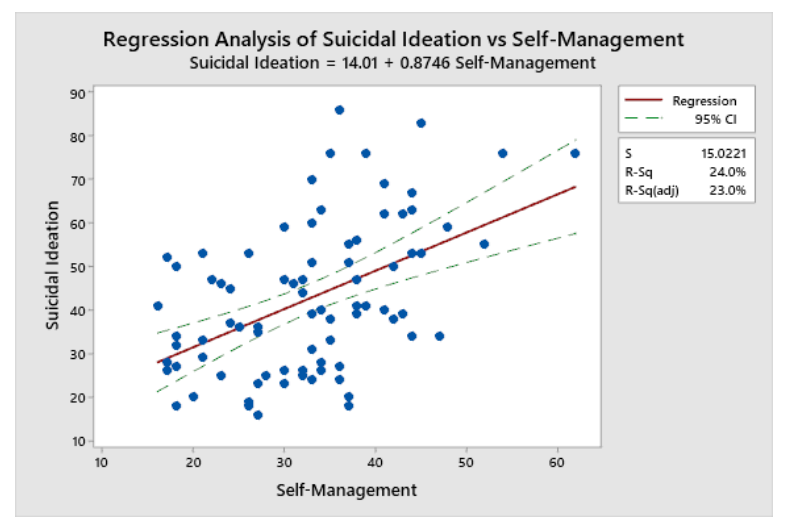

Fig. 1. Scatter plot with regression analysis of suicidal ideation against self-management.

Further regression analyses were conducted to determine the significance of this regression model (as depicted in Figure 1). Analysis of Variance with the Student's t-test was conducted to test the following hypothesis:

$\mathrm{H}_{0}$ : Slope coefficient (self-management) is equal to 0

$\mathrm{H}_{1}$ : Slope (self-management) is not equal to 0

T-test revealed a t-value of 4.4912. Assuming a significance level, $\alpha$ of 0.001 , for sample size of 81 , the $\mathrm{t}$-value is 3.416 . Therefore, the null hypothesis, $\mathrm{H}_{0}$ is rejected and the alternative hypothesis, $\mathrm{H}_{1}$ is accepted.

Past research has also supported the relationship between suicidal ideation and selfmanagement. Richardson et al. (2005) studied on the perceived academic performance (PAP) as an indicator of risk suicidal behavior in young adolescents. The study found that students who reported their academic performance as failing are more likely to report on suicidal thoughts, plans and threats. Through extensive logistic regression study, they determined that depressive symptomology decreased only when higher PAP was reported. Self-management factor also aligns with cognition aspect of the multimodal BASIC ID tool which is used for suicide assessment (Paladino \& Minton, 2008). Cognition which includes one's thoughts, or 
attitude about a certain experience could range from dichotomous thinking to overt overgeneralizations (Lazarus, 2006). For instance, students with suicidal ideation may often believe that they are incapable of going through a semester, let alone life (Palladino \& Minton, 2008). This is in line with the "I do not feel confident with my own capabilities" issue highlighted in HENIs.

\section{Recommendations and possibility of future works}

It should be noted that since HENIs survey was presented directly to academic probation students, there is a possibility of self-reporting bias. For instance, academic probation students might not be aware of the severity of the issue that they face. Future study could include external assessment by academic probation students' mentor. Data is only considered valid if responses from both parties are consistent.

\section{Conclusion}

This study has managed to determine intrapersonal factors that affect academic performance among academic probation students of Universiti Teknologi PETRONAS. Results from HENIs revealed that self-management, finance and health are the three highest factors that affect academic probation students with a HENIs Index of 2.52, 2.38 and 2.17, respectively. In addition, it was determined that issue in self-management of academic probation students showed positive correlation with suicidal ideation with a $\mathrm{R}^{2}$ value of 0.2400 ( $\mathrm{p}$-value of $0.001)$.

The content of this study is the responsibility of the authors and does not necessarily reflect official views of the Universiti Teknologi PETRONAS. The authors would like to extend their deepest gratitude to the Psychological and Counselling Department, UTP for providing the necessary permission to carry out this pilot study utilizing HENIs. The authors would also like to thank the students that participated in this study.

\section{REFERENCES}

1. Adams, T., \& Moore, M. (2007). High-risk health and credit behavior among 18-to 25-yearold college students. Journal of American College Health, 56(2), 101-108.

2. Akinsola, M. K., Tella, A., \& Tella, A. (2007). Correlates of academic procrastination and mathematics achievement of university undergraduate students. Eurasia Journal of Mathematics, Science \& Technology Education, 3(4), 363-370.

3. Benjamin, S. J., Marathamuthu, M. S., Muthaiyah, S., \& Raman, M. (2011). Affordability of private tertiary education: a Malaysian study. International Journal of Social Economics.

4. Britton, B. K., \& Tesser, A. (1991). Effects of time-management practices on college grades. Journal of Educational Psychology, 83(3), 405.

5. Bunce, L., Baird, A., \& Jones, S. E. (2017). The student-as-consumer approach in higher education and its effects on academic performance. Studies in Higher Education, 42(11), 1958-1978.

6. Bunyaan, S. A., Tan, S. I., \& Loo, Y. M. (2015). Emotional Intelligence and Academic Achievement: A Study Among Students of a Private University in Malaysia. Paper presented at the Taylor's 7th Teaching and Learning Conference 2014 Proceedings.

7. Catharino, A., Catharino, F., \& Fonseca, R. (2007). Headache: prevalence and relationship with the academic performance of medical students. Migraneas Cefaléias, 10, 46-50. 
8. Cheong, K.-C., Hill, C., Leong, Y.-C., \& Zhang, C. (2018). Employment as a journey or a destination? Interpreting graduates' and employers' perceptions-a Malaysia case study. Studies in Higher Education, 43(4), 702-718.

9. Choi, J. N., \& Moran, S. V. (2009). Why not procrastinate? Development and validation of a new active procrastination scale. The Journal of Social Psychology, 149(2), 195-212.

10. Demirkirkan, M. K., Ellidokuz, H., \& Boluk, A. (2006). Prevalence and clinical characteristics of migraine in university students in Turkey. The Tohoku Journal of Experimental Medicine, 208(1), 87-92.

11. Elias, H., Ping, W. S., \& Abdullah, M. C. (2011). Stress and academic achievement among undergraduate students in Universiti Putra Malaysia. Procedia-Social and Behavioral Sciences, 29, 646-655.

12. Falavigna, A., Teles, A. R., Velho, M. C., Vedana, V. M., Silva, R. C. d., Mazzocchin, T., . . . Braga, G. L. (2010). Prevalence and impact of headache in undergraduate students in Southern Brazil. Arquivos de Neuro-Psiquiatria, 68(6), 873-877.

13. Gaultney, J. F. (2010). The prevalence of sleep disorders in college students: impact on academic performance. Journal of American College Health, 59(2), 91-97.

14. Group, S., dos Santos, S. G., \& Moro, A. R. P. (2010). Descriptive study on sagittal lumbar spine changes in students of the federal educational system of Florianópolis. Revista Brasileira de Ortopedia, 45(5), 453-459.

15. Hogan, E., Bryant, S., \& Overymyer-Day, L. (2013). Relationships between college students' credit card debt, undesirable academic behaviors and cognitions, and academic performance. College Student Journal, 47(1), 102-112.

16. Issa, L. F., Seleem, N., Bakheit, A., Baky, A., \& Alotaibi, A. (2016). Low back pain among undergraduate students at Taif University-Saudi Arabia. International Journal of Public Health and Epidemiology, 276-284.

17. Kim, K. R., \& Seo, E. H. (2015). The relationship between procrastination and academic performance: A meta-analysis. Personality and Individual Differences, 82, 26-33.

18. Kukulu, K., Korukcu, O., Ozdemir, Y., Bezci, A., \& Calik, C. (2013). Self-confidence, gender and academic achievement of undergraduate nursing students. Journal of Psychiatric and Mental Health Nursing, 20(4), 330-335.

19. Lakshminarayan, N., Potdar, S., \& Reddy, S. G. (2013). Relationship between procrastination and academic performance among a group of undergraduate dental students in India. Journal of Dental Education, 77(4), 524-528.

20. Lane, J., Lane, A. M., \& Kyprianou, A. (2004). Self-efficacy, self-esteem and their impact on academic performance. Social Behavior and Personality: an International Journal, 32(3), 247-256.

21. Latif, L. A. (2006). Academic Counseling as a Pro-Active Retention Initiative at Open University Malaysia (OUM). Paper presented at the 6th SEAAIR Annual Conference, Langkawi, Malaysia.

22. Lazarus, A. (2006). Brief but comprehensive psychotherapy: The multimodal way: Springer Publishing Company.

23. Lepp, A., Barkley, J. E., Sanders, G. J., Rebold, M., \& Gates, P. (2013). The relationship between cell phone use, physical and sedentary activity, and cardiorespiratory fitness in a sample of US college students. International Journal of Behavioral Nutrition and Physical Activity, 10(1), 79. 
24. Macan, T. H., Shahani, C., Dipboye, R. L., \& Phillips, A. P. (1990). College students' time management: Correlations with academic performance and stress. Journal of Educational Psychology, 82(4), 760.

25. Malaysian Ministry of Education. (2018). Quick Facts 2018 - Malaysia Educational Statistics. Retrieved from Putrajaya:

26. Montgomery, S., Gregg, D. H., Somers, C. L., Pernice-Duca, F., Hoffman, A., \& Beeghly, M. (2019). Intrapersonal variables associated with academic adjustment in United States college students. Current Psychology, 38(1), 40-49.

27. Nor, P. N. S. M. M., Ismail, S. (2015). Effect of Industrial Training on Academic Performance: Evidence from Malaysia. Journal of Technical Education and Training, 7(2).

28. Paladino, D., \& Minton, C. A. B. (2008). Comprehensive college student suicide assessment: application of the BASIC ID. Journal of American College Health, 56(6), 643-650.

29. Rainville, J., Hartigan, C., Martinez, E., Limke, J., Jouve, C., \& Finno, M. (2004). Exercise as a treatment for chronic low back pain. The Spine Journal, 4(1), 106-115.

30. Ramasamy, M., Apadore, K., Mohamad, Z. Z., \& Letchumanan, T. R. (2018). Understanding of learning styles among international and local students on academic performance in higher education institution in Malaysia. International Journal of Education, 3(17), 68-84.

31. Rice, K. G., \& Mirzadeh, S. A. (2000). Perfectionism, attachment, and adjustment. Journal of Counseling Psychology, 47(2), 238.

32. Richardson, A. S., Bergen, H. A., Martin, G., Roeger, L., \& Allison, S.. (2005). Perceived academic performance as an indicator of risk of attempted suicide in young adolescents. Archives of Suicide Research, 9(2), 163-176.

33. Rocha-Filho, P. A., \& Santos, P. V. (2014). Headaches, quality of life, and academic performance in schoolchildren and adolescents. Headache: The Journal of Head and Face Pain, 54(7), 1194-1202.

34. Siraj, H. H., Salam, A., Hasan, N. A. B., Jin, T. H., Roslan, R. B., \& Othman, M. N. B. (2015). Internet usage and academic performance: a study in a Malaysian public university. Journal of International Medical Journal, 22(2), 83-86.

35. Souza-e-Silva, H. R., \& Rocha-Filho, P. A. (2011). Headaches and academic performance in university students: A cross-sectional study. The Journal of Head and Face Pain, 51(10), 1493-1502.

36. Tice, D. M., \& Baumeister, R. (1997). Longitudinal study of procrastination, performance, stress, and health: The costs and benefits of dawdling. Psychological Science, 8(6), 454-458.

37. Ting, T. T., Ng, K. S., Ooi, K. H., \& Yap, C. Y. (2018). Current Impact of Social Media on Higher Education Institution Student's Academic Performance in Malaysia. J Advanced Science Letters, 24(4), 2247-2251.

38. Winterrowd, E., Priniski, S. J., Achter, J., \& Abhold, J. J. J. C. S. J. (2016). Correlates of satisfaction, intrapersonal learning, and academic outcomes at counseling centers in a university system. College Student Journal, 50(2), 288-301.

39. Yang, C.-M., Wu, C.-H., Hsieh, M.-H., Liu, M.-H., \& Lu, F.-H. (2003). Coping with sleep disturbances among young adults: a survey of first-year college students in Taiwan. Behavioral Medicine, 29(3), 133-138.

40.Zakaria, R., Satari, S., Damahuri, N., \& Khairuddin, R. (2019). Descriptive Analysis of Students' CGPA: A Case Study of Universiti Malaysia Pahang. Paper presented at the IOP Conference Series: Materials Science and Engineering. 